\title{
Factors affecting the choice of postgraduate specialty among undergraduate medical students: a prospective observational study from India
}

\author{
Chawla, J. ${ }^{1}$, Arora, M. ${ }^{2}$, Datta, K. ${ }^{3}$, Singh, S.P. ${ }^{4}$, Arora, A. ${ }^{5}$
}

\begin{abstract}
Purpose: National policies on the number and distribution of post graduate seats in medical colleges are based on estimated projections of the quantum need of medical work force in the country in future. In order to attract talent, it is imperative to know what factors, modifiable or non modifiable, affect the choice of specialization.

Methods: This is a cross-sectional, observational study. Subjects were undergraduate medical students, at four different phases of their course. They were asked to fill an anonymous feedback form regarding their family and educational background and prospective fields of specialization and placement. Medium of education, interaction with faculty, practices of evaluation and feedback to and from students and use of media in teaching etc were also studied in order to gain an insight into the temporal progression of the thought process of undergraduates.
\end{abstract}

Results: Majority (88.5\%) students wanted to study clinical subjects in post graduation. General Medicine and General Surgery were the most coveted specialties. Passion for the subject, monetary gains and how well the subject was taught were the three main bases for the choice of specialty. Majority of students wanted to serve in government sector after study. Work life balance remained the top priority for more than $78 \%$ students in their future lives.

Conclusion: Clinical branches remain preferred over non clinical specialties and research remains a low priority among students. Introducing innovative methods in teaching pre and paraclinical subjects and making medical teaching a more attractive career prospect can help improve this picture.

Key words: Undergraduate, Medical, Education, Priority.

\section{Introduction}

National policies on the number and distribution of postgraduate seats in medical colleges are based on estimated projections of the quantum need of medical work force in the country in times to come.

\footnotetext{
${ }^{1}$ Assistant Professor, Department of Obstetrics \& Gynecology, PGIMER \& Dr. RML Hospital, New Delhi, India

${ }^{2}$ Assistant Professor, Department of Community Medicine, Army College of Medical Sciences, New Delhi, India

${ }^{3}$ Professor, Department of Physiology, Armed Forces Medical College, Pune

${ }^{4}$ Undergraduate medical student, Army College of Medical Sciences, New Delhi, India

${ }^{5}$ Undergraduate medical student, Sikkim Manipal Institute of Medical Sciences, Tadong, Gangtok, Sikkim

Corresponding Author:

Dr. Jaya Chawla, Assistant Professor, Department of Obstetrics \& Gynaecology, PGIMER \& Dr. RML Hospital, New Delhi, India

E mail: jayachawla51@yahoo.com
}

DOI: http://doi.org/10.4038/seajme.v12i2.50
In order to attract the right people for the right job, it is imperative to know what factors, modifiable or non modifiable, affect the choice of specialization. In addition, ways of teaching can also have a great impact on the young minds. The potential to customize the choices of the work force in the country can be efficiently tapped to bridge the gap between demand and supply of medical practitioners and research scholars.

Studies conducted in the United States (Newton et al., 2005) and China (She et al., 2008) indicate that most undergraduates are inclined towards a career in clinical specialties and research is a priority lower down on scale of aspirations. The basis of selection for most students is monetary returns associated with a particular branch. Most students fluent in English and conversant with the use of computers are unlikely to be undecided in the 
choice of their future careers. However a study from Nigeria (Odusanya et al., 2000) found a different set of basis for choice of specialization. The main reasons influencing specialization were primary interest in the specialty $(91 \%)$, service to humanity $(91 \%)$ and job satisfaction (85.7\%).

Scarcity of doctors is a well known phenomenon. Paucity of medical colleges to impart quality medical education is often cited as a reason for this problem in addition to issues of brain drain and disdain from joining rural service. More and more efflux of doctors to urban locations results in decreased skilled work force in rural areas and decreased income and level of satisfaction among urban professionals.

Cleland et al. (2014) from UK in their study describe how the teaching in medical school in itself alters and shapes career preferences. They however emphasize the need for more longitudinal studies to acquire more robust data in support of this hypothesis.

Thus, we decided to conduct a cross sectional study to understand and analyze the various factors that influence or are associated with the choice of specialization and the priorities which shape this decision, among undergraduate students.

\section{Aim}

To study factors associated with the choice of specialization among under graduate medical students in different stages of undergraduate course.

\section{Objectives}

1. To estimate the prevalence of various specialties as choices among undergraduate medical students and associated with the preferences over five years of undergraduate study.

2. To study the factors associated with the student's preference towards choice of specialty and placement in later life.

3. To study priorities of young undergraduates in their future plans.

\section{Methods}

This cross-sectional, observational study was conducted at a medical college in the national capital. The subjects were undergraduate medical students, at four different phases of their course to analyze their choice of subject of specialization and factors that are associated with it.

Students from the entry year, second year, third year and exit year, representing the outgoing batch were recruited for this study (Figure 1). An anonymous feedback form was prepared after thorough brain storming with preclinical, paraclinical and clinical faculty and also medical education faculty. The feedback form was designed to be a comprehensive document that aimed to gather as much information as was realistically possible about all factors, both direct and indirect, that could have a potential impact on the choice of specialty of a medical undergraduate. The students were asked to fill an anonymous feedback form regarding their family and educational background and prospective fields of specialization and placement.

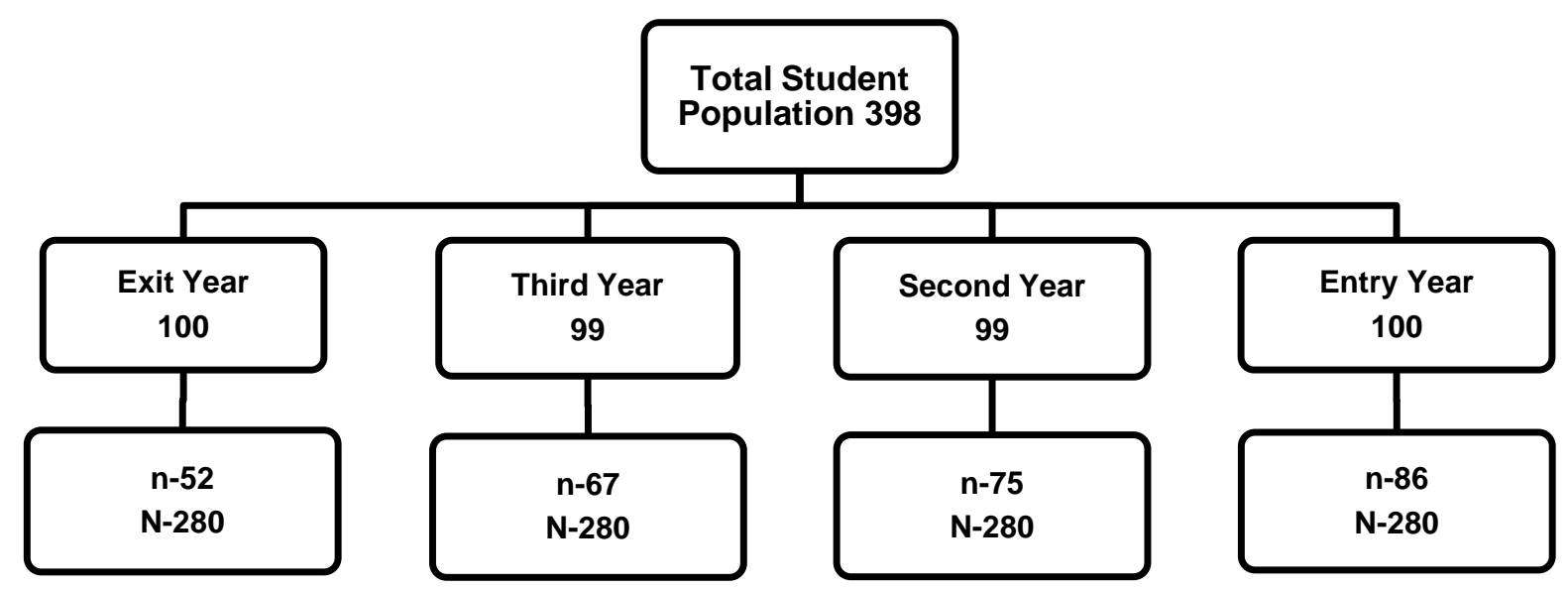

Figure 1: Sample Frame and Sampling 
Various aspects of undergraduate teaching such as, medium of education, interaction with faculty, practices of evaluation, feedback to and from students etc were enquired about. Their preferences with respect to language and media for teaching employed in their subjects of preference were also studied in order to gain an insight into the temporal progression of the thought process of young undergraduates.

The data was collected on different days from each of the batches. The feedback form was distributed in a teaching session to the students who were present on the day of data collection. The participation was voluntary and a written consent was obtained from the students who were willing to participate. The data thus obtained was analyzed to answer the study questions. A total of 280 students filled the form. The present study was approved by the Institutional ethical committee of the medical college.

\section{Data analysis}

Descriptive and inferential statistics were carried out. Inferential statistics utilized the Chi square test and Statistical package for social sciences (SPSS) version 20 was used for analysis. A $p$ value $<0.05$ was considered as statistically significant. Since initially factors which could even remotely bear an influence were included in the feedback form, some of the data for which no meaningful association could be deduced or where sample size was found to be too small to draw a reasonable conclusion were later taken away from the final results.

\section{Results}

Of the 280 students who participated in the study, $129(46.1 \%)$ were males and 151 (53.9\%) females. Overall, the average age of the study participants was 20.99 years (+2.231) (Table 1). 92.5\% students had English as the medium of education in the institute last attended. Overall $85.8 \%$ students came from defense backgrounds, and nearly $80 \%$ mothers were home makers.

Table 1: Age and Gender distribution of the participants

\begin{tabular}{lccc}
\hline Year & Mean Age in Years (₫SD) & Male N (\%) & Female N (\%) \\
\hline Entry & $19.21(1.228 \%)$ & $47(54.7 \%)$ & $39(45.3 \%)$ \\
Second & $20.33(1.349 \%)$ & $37(49.3 \%)$ & $38(50.7 \%)$ \\
Third & $21.28(1.126 \%)$ & $18(26.9 \%)$ & $49(73.1 \%)$ \\
Exit & $24.5(1.336 \%)$ & $27(51.9 \%)$ & $25(48.1 \%)$ \\
\hline
\end{tabular}

More than half the students cleared the entrance exam for entry into medicine course in their second attempt which shows their perseverance towards their chosen profession. $77 \%$ respondents had history of multiple attempts at entry.

Passion for the field was the leading cause why people chose medicine accounting for $36 \%$ followed by desire to serve society $(26 \%)$ and to deserve respect from society $(18 \%)$. A sizeable more than $16 \%$ were influenced by their families and only $10 \%$ considered monetary gains while they chose this profession.

With the help of our feedback forms, we tried to elucidate the extent of technological proficiency of our students on a cross sectional basis. The idea was to estimate their efficiency depending on whether they could confidently prepare a word document/a power point presentation/a website. While in the entry level batch, only $65.1 \%$ students could create power points with ease, this number sequentially rose to $66.7 \%, 80.6 \%$ and $92.3 \%$ through successive batches.

Nearly half of the participants wanted to pursue post graduation and another 50\% super specialization. The students aiming at super specialization consistently increased from $46.5 \%$ in the junior most batch to $48 \%$ in second year, $50.7 \%$ in third year and $53.8 \%$ in the exit batch. The corresponding figures for graduation only plummeted from $4.7 \%$ in the entrant batch to zero in the outgoing batch (Table 2). 
Table 2: Year wise distribution of choice of speciality

\begin{tabular}{lccccc}
\hline & $\begin{array}{c}\text { Entry Year } \\
\mathbf{N}(\%)\end{array}$ & $\begin{array}{c}\text { Second year } \\
\mathbf{N}(\%)\end{array}$ & $\begin{array}{c}\text { Third year } \\
\mathbf{N}(\%)\end{array}$ & $\begin{array}{c}\text { Exit year } \\
\mathbf{N}(\%)\end{array}$ & $\begin{array}{c}\text { Overall } \\
\mathbf{N}(\%)\end{array}$ \\
\hline Nonclinical & $23(26.7 \%)$ & $5(6.7 \%)$ & $1(1.5 \%)$ & $3(5.8 \%)$ & $32(11.4 \%)$ \\
Clinical & $34(39.5 \%)$ & $63(84 \%)$ & $63(94 \%)$ & $46(88.5 \%)$ & $206(73.6 \%)$ \\
Not Decided & $29(33.7 \%)$ & $7(9.3 \%)$ & $3(4.5 \%)$ & $3(5.8 \%)$ & $42(15 \%)$ \\
Overall & $86(100 \%)$ & $75(100 \%)$ & $67(100 \%)$ & $52(100 \%)$ & $280(100 \%)$ \\
\hline
\end{tabular}

Specialties were broadly classified into NonClinical and Clinical. Non Clinical specialties included Anatomy, Physiology, Biochemistry, Pathology, Pharmacology, Microbiology, Forensic Medicine and Community Medicine. Clinical specialties included Ophthalmology, ENT, Surgery, Medicine, Gynecology and Obstetrics, Paediatrics, Orthopedics, Dermatology, Anesthesia, Radiology and Psychiatry.
As expected, with seniority the proportion of students who had not decided upon their choice of specialization reduced. At the point of entry into a medical college $39.5 \%$ students wanted to opt for clinical branches. This figure rose to $88.5 \%$ by the time they spent five years in the field and were about to appear for their qualifying exam for entry to post graduation. Correspondingly, the percentage of students keen to take up preclinical subjects dived from $26.7 \%$ in the first year to $5.8 \%$ in the exit year (Table 3).

Table 3: Year and subject wise distribution of specialty preference

\begin{tabular}{lccccc}
\hline & $\begin{array}{c}\text { Entry year } \\
\mathbf{N}(\%)\end{array}$ & $\begin{array}{c}\text { Second year } \\
\mathbf{N}(\%)\end{array}$ & $\begin{array}{c}\text { Third year } \\
\mathbf{N}(\%)\end{array}$ & $\begin{array}{c}\text { Exit year } \\
\mathbf{N}(\%)\end{array}$ & $\begin{array}{c}\text { Overall } \\
\mathbf{N}(\%)\end{array}$ \\
\hline Anatomy & $1(1.2 \%)$ & $0(0 \%)$ & $0(0 \%)$ & $0(0 \%)$ & $1(0.4 \%)$ \\
Physiology & $11(10.8 \%)$ & $3(4 \%)$ & $0(0 \%)$ & $0(05)$ & $14(5 \%)$ \\
Biochemistry & $0(0 \%)$ & $1(1.3 \%)$ & $1(1.5 \%)$ & $0(0 \%)$ & $2(0.7 \%)$ \\
Pharmacology & $0(0 \%)$ & $0(0 \%)$ & $0(0 \%)$ & $1(1.9 \%)$ & $1(0.4 \%)$ \\
Microbiology & $2(2.3 \%)$ & $0(0 \%)$ & $0(0 \%)$ & $0(0 \%)$ & $2(0.75)$ \\
Forensic Medicine & $4(4.7 \%)$ & $0(0 \%)$ & $0(0 \%)$ & $0(0 \%)$ & $4(1.4 \%)$ \\
Pathology & $4(4.7 \%)$ & $1(1.3 \%)$ & $0(0 \%)$ & $1(1.9 \%)$ & $6(2.1 \%)$ \\
Medicine & $4(4.7 \%)$ & $22(29.3 \%)$ & $19(28.4 \%)$ & $10(19.2 \%)$ & $55(19.6 \%)$ \\
Surgery & $20(23.3 \%)$ & $16(21.3 \%)$ & $9(13.4 \%)$ & $10(19.2 \%)$ & $55(19.6 \%)$ \\
Dermatology & $0(0 \%)$ & $6(8 \%)$ & $9(13.4 \%)$ & $4(7.7 \%)$ & $19(6.8 \%)$ \\
Obstetrics/Gynecology & $1(1.2 \%)$ & $3(4 \%)$ & $5(7.5 \%)$ & $5(9.6 \%)$ & $14(5 \%)$ \\
Anaesthesia & $0(0 \%)$ & $1(1.3 \%)$ & $0(0 \%)$ & $0(0 \%)$ & $1(0.4 \%)$ \\
Psychiatry & $2(2.3 \%)$ & $3(4 \%)$ & $3(4.5 \%)$ & $0(0 \%)$ & $8(2.9 \%)$ \\
ENT & $0(0 \%)$ & $1(1.3 \%)$ & $0(0 \%)$ & $0(0 \%)$ & $1(0.4 \%)$ \\
Ophthalmology & $2(2.3 \%)$ & $2(2.7 \%)$ & $2(3 \%)$ & $1(1.9 \%)$ & $7(2.5 \%)$ \\
Community Medicine & $1(1.2 \%)$ & $0(0 \%)$ & $0(0 \%)$ & $1(1.9 \%)$ & $2(0.75)$ \\
Radiology & $3(3.5 \%)$ & $2(2.7 \%)$ & $5(7.5 \%)$ & $2(3.8 \%)$ & $12(4.3 \%)$ \\
Paediatrics & $2(2.3 \%)$ & $6(8 \%)$ & $6(9 \%)$ & $9(17.3 \%)$ & $23(8.2 \%)$ \\
Orthopaedics & $0(0 \%)$ & $1(1.35)$ & $5(7.5 \%)$ & $5(9.6 \%)$ & $11(3.9 \%)$ \\
Not decided & $29(33.7 \%)$ & $7(9.3 \%)$ & $3(4.5 \%)$ & $3(5.85)$ & $42(15 \%)$ \\
Overall & $86(100 \%)$ & $75(100 \%)$ & $67(100 \%)$ & $52(100 \%)$ & $280(100 \%)$ \\
\hline & & & & &
\end{tabular}


It is remarkable that in the entry year, $12 \%$ participants were keen on taking up pre clinical subjects, namely, Anatomy and Physiology for specialization which decreased to nil by the end of undergraduate education, as they were exposed to other streams, $9.7 \%$ people wanted to opt for paraclinical subjects, namely Microbiology and Forensic science in the initial year of medical studies and this reduced to $3.8 \%$ by the end. Dermatology, Psychiatry, Obstetrics and Gynecology, Paediatrics and Orthopedics were branches that consistently showed increasing uptake through the course of medical study. Overall, General Medicine
(19.6\%) and General Surgery (19.6\%) were most sought after streams followed by Paediatrics (8.2\%).

It is their passion for a branch and not money as is popularly believed, that guided the student's choice of specialty in this anonymous study. $68.5 \%$ students based their choice on passion for the branch followed by $19.3 \%$ who kept the monetary returns in mind while taking this decision. $11.3 \%$ responders chose the subject since it was well taught in college (Table 4).

Table4: Reasons for choice of speciality

\begin{tabular}{lccccc}
\hline Reason & $\begin{array}{c}\text { Entry year } \\
\mathbf{N}(\%)\end{array}$ & $\begin{array}{c}\text { Second year } \\
\mathbf{N}(\%)\end{array}$ & $\begin{array}{c}\text { Third year } \\
\mathbf{N}(\%)\end{array}$ & $\begin{array}{c}\text { Exit year } \\
\mathbf{N}(\%)\end{array}$ & $\begin{array}{c}\text { Overall } \\
\mathbf{N}(\%)\end{array}$ \\
\hline Passion for the subject & $43(75.4 \%)$ & $45(66.2 \%)$ & $45(70.3 \%)$ & $30(61.2 \%)$ & $163(68.5 \%)$ \\
Well paying branch & $8(14 \%)$ & $18(26.5 \%)$ & $10(15.6 \%)$ & $12(24.5 \%)$ & $48(20.2 \%)$ \\
Subject taught well & $6(10.5 \%)$ & $5(7.4 \%)$ & $9(14.1 \%)$ & $7(14.3 \%)$ & $27(11.3 \%)$ \\
Overall & $57(100 \%)$ & $68(100 \%)$ & $64(100 \%)$ & $49(100 \%)$ & $238(100 \%)$ \\
\hline
\end{tabular}

To assess factors associated with choice of specialty, Chi square analysis was carried out. Since 42 students were undecided on the choice of specialty, a study sample of 238 students was used for this analysis. It was observed that preference for clinical specialties significantly increased with age. $93.9 \%$ of students aged more than 21 years chose a clinical specialty as compared to $82.7 \%$ students aged 21 or less $(p=0.016)$ (Table 5).

Table 5: Results of Chi square analysis for association with choice of speciality

\begin{tabular}{llcccc}
\hline Variables & Criteria & $\begin{array}{c}\text { Non-Clinical } \\
\text { N (\%) }\end{array}$ & $\begin{array}{c}\text { Clinical } \\
\text { N (\%) }\end{array}$ & $\begin{array}{c}\text { Overall } \\
\text { N (\%) }\end{array}$ & p value \\
\hline \multirow{3}{*}{ Age } & 21 or less & $27(17.3 \%)$ & $129(82.7 \%)$ & $156(100 \%)$ & \\
& More than 21 & $5(6.1 \%)$ & $77(93.9 \%)$ & $82(1005)$ & 0.016 \\
& Overall & $32(13.4 \%)$ & $206(86.6 \%)$ & $238(100 \%)$ & \\
\hline \multirow{3}{*}{ Gender } & Male & $20(18.2 \%)$ & $90(81.8 \%)$ & $110(100 \%)$ & \\
& Female & $12(9.4 \%)$ & $116(90.6 \%)$ & $128(100 \%)$ & 0.047 \\
& Overall & $32(13.4 \%)$ & $206(86.8 \%)$ & $238(100 \%)$ & \\
\hline \multirow{4}{*}{ Year } & Entry & $23(40.4 \%)$ & $34(59.6 \%)$ & $57(100 \%)$ & \\
& Second & $5(7.4 \%)$ & $63(92.6 \%)$ & $68(100 \%)$ & \\
& Third & $1(1.6 \%)$ & $63(98.4 \%)$ & $64(100 \%)$ & 0.000 \\
& Exit & $3(6.1 \%)$ & $46(93.1 \%)$ & $49(100 \%)$ & \\
& Overall & $32(13.4 \%)$ & $206(86.8 \%)$ & $238(100 \%)$ & \\
\multirow{2}{*}{$\begin{array}{l}\text { Reasons for } \\
\text { choice of } \\
\text { speciality }\end{array}$} & Passion for the subject & $26(16 \%)$ & $137(84 \%)$ & $163(100 \%)$ & \\
& Well paying branch & $2(4.2 \%)$ & $46(95.85)$ & $48(100 \%)$ & \multirow{2}{*}{0.107} \\
& Subject taught well & $4(14.8 \%)$ & $23(85.2 \%)$ & $27(100 \%)$ & \\
\hline
\end{tabular}


Gender analysis for choice of specialty revealed that the proportion of female students choosing a clinical specialty was significantly higher $(90.6 \%)$ than the male students $(81.8 \%)$ $(p-0.047)$. Among the entry batch students, $59.6 \%$ and $40.6 \%$ students opted for clinical specialty and non-clinical specialties respectively. This is in contrast to the exit batch students where $93.1 \%$ and $6.1 \%$ opted for clinical and non-clinical specialties respectively. Thus there is statistically significant difference across the batches ( $p$ 0.000).

The question on the biggest influence in their lives was kept anticipating that they would name stalwarts in their field or faculty which could be their basis for choosing a particular specialty. However the question was deliberately kept open ended so as to get a better understanding of who genuinely influenced the young minds to the greatest extent. The responses were as follows. Parents continued to be the biggest influence $(79.6 \%)$ in the lives of people who were pursuing higher education and were in general 20 years and above at the time of responding to this study. This was followed by $8.2 \%$ for siblings, $6.4 \%$ for friends.

When asked about their plans for ultimate placement choices in life, responders made some startling revelations. Contrary to popular perception only $10 \%$ students wanted to settle abroad. Almost an equal percentage of students $(9.3 \%)$ were willing to serve in rural areas as well. As good as 74\% (government sector and armed forces combined) intended to not only stay in the country but also serve the government. However, what should incite internal audit is the fact that only $5.4 \%$ wanted to become faculty. This reflects our general apathy towards teachers as a society (Table $6)$.

Table 6: Placement plans

\begin{tabular}{lccccc}
\hline & $\begin{array}{c}\text { Entry year } \\
\mathbf{N}(\%)\end{array}$ & $\begin{array}{c}\text { Second year } \\
\mathbf{N}(\%)\end{array}$ & $\begin{array}{c}\text { Third year } \\
\mathbf{N}(\%)\end{array}$ & $\begin{array}{c}\text { Exit year } \\
\mathbf{N}(\%)\end{array}$ & $\begin{array}{c}\text { Overall } \\
\mathbf{N}(\%)\end{array}$ \\
\hline Government & $27(31.4 \%)$ & $29(38.7 \%)$ & $32(47.8 \%)$ & $19(36.5 \%)$ & $107(38.2 \%)$ \\
Armed Forces & $32(37.2 \%)$ & $24(32 \%)$ & $25(37.3 \%)$ & $15(28.8 \%)$ & $96(34.3 \%)$ \\
Private sector & $18(14 \%)$ & $31(21.3 \%)$ & $17(16.4 \%)$ & $21(21.2 \%)$ & $87(17.9 \%)$ \\
Medical research & $24(27.9 \%)$ & $16(21.3 \%)$ & $5(7.5 \%)$ & $3(5.8 \%)$ & $48(17.9 \%)$ \\
Settle abroad & $9(10.5 \%)$ & $5(6.7 \%)$ & $9(13.4 \%)$ & $5(9.6 \%)$ & $28(10 \%)$ \\
Settle in rural areas & $5(5.85 \%)$ & $8(10.7 \%)$ & $10(14.9 \%)$ & $3(5.8 \%)$ & $26(9.3 \%)$ \\
Teaching & $4(4.7 \%)$ & $4(5.3 \%)$ & $4(6 \%)$ & $3(5.8 \%)$ & $15(5.4 \%)$ \\
\hline
\end{tabular}

It is food for thought that the inclination for medical research, consistently decreased over the years in under graduate education, pegging at $27.9 \%$ in the entry batch and getting reduced to less than a quarter of this figure $(5.8 \%)$ in the exit batch.

We tried to delve a little deeper and understand the long term priorities in the lives of these young, promising doctors. $78 \%$ participants chose work life balance as their top priority in life followed almost equally, by money $(20.7 \%)$ and choice of specialty $(20 \%)$.

Research and academics came lower down at $11.8 \%$ reiterating the earlier observation that fewer people want to join faculty positions. Remarkably, the interest in academics and research is consistently a downward spiral from entry to exit, being $14 \%$ in entry year, $13.3 \%$ in second, $11.9 \%$ in third and only $5.8 \%$ in the exit year.
Since the manner in which these young minds are imparted education has an important impact on their choice of branch later, we sought information on how they preferred to be taught. More than $40 \%$ students preferred chalk and board teaching and interactive sessions as compared to power point presentations. Even a combination of the two modalities of teaching was not very popular with medical students as only $11.8 \%$ participants preferred it. 30.7\% respondents did not respond to this question.

The preference for chalk and board teaching only increased with each passing year of undergraduate teaching, doubling from $31.4 \%$ in the entry batch to $61.5 \%$ in the exit batch. The corresponding rates for audio visual aids were $18.6 \%$ in the entry batch, falling to $7.7 \%$ in the exit batch (Figure 2). This is surprising bearing in mind that the technological proficiency of these students had consistently risen from entry to exit in the institute. 


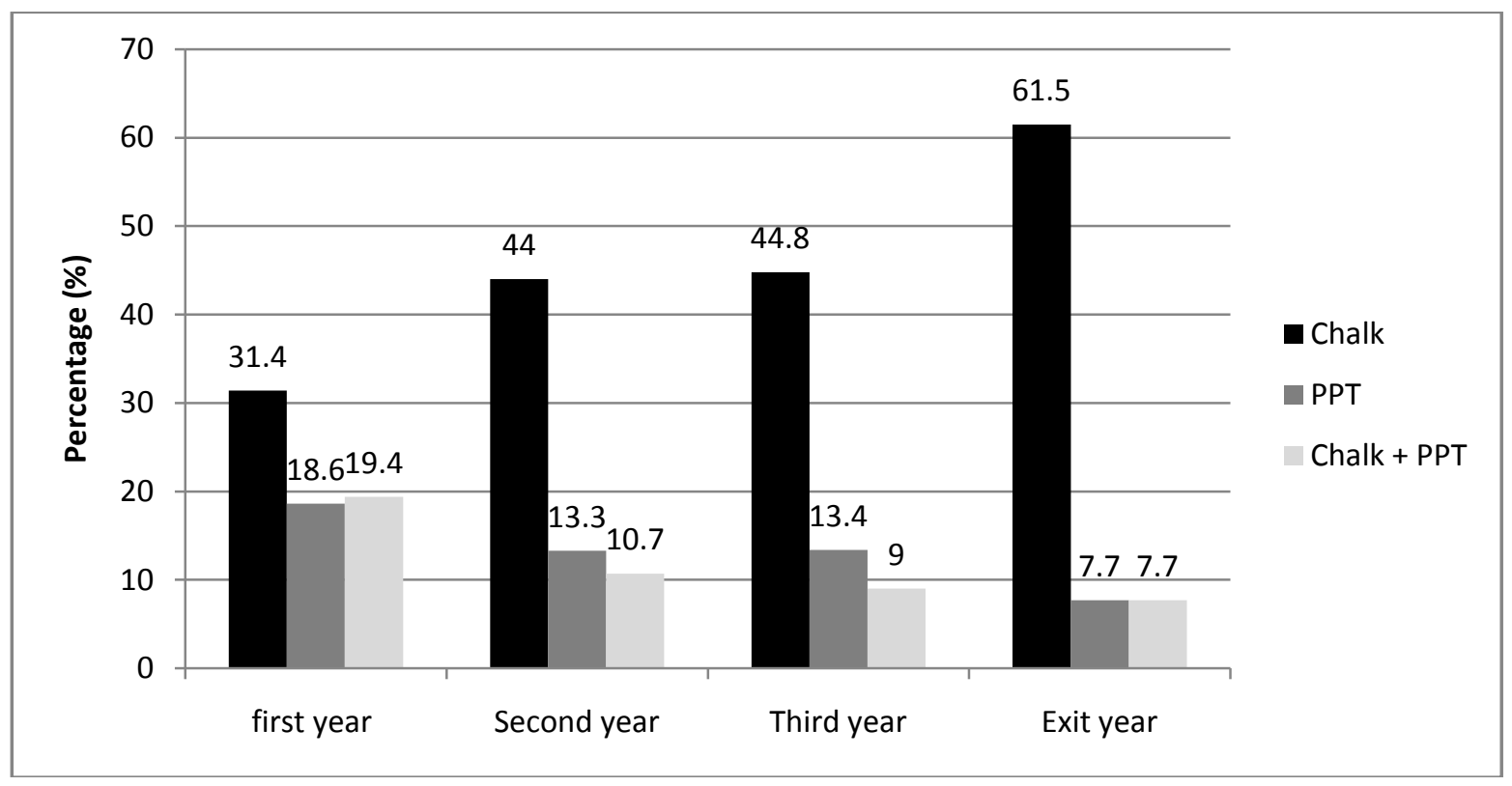

Figure 2: Showing preference of teaching methods by the students

\section{Discussion}

In this study on preferences of medical undergraduates, clinical branches clearly scored over diagnostic and preclinical branches. This is similar to the findings of the study from UK conducted across four medical colleges where clinical branches were among the first seven most sought after followed by diagnostics at number eight (Cleland et al., 2014). The phenomenon was consistent among entry and exit level cohorts. In the study from Nigeria as well the top five specialties, namely Obstetrics and Gynecology, Surgery, Paediatrics, Anesthesia and Psychiatry were clinical (Okonta et al., 2015). Reports from Germany have reported similar results (Götz et al., 2011). However, in reports from China, research seemed to be gaining popularity among medical undergraduates (She et al., 2008).

$10.8 \%$ of our first year students chose Physiology as their preferred subject of specialization followed by $1.2 \%$ for Anatomy. The preference for paraclinical subjects in first year was $4.7 \%$ each for Pathology and Forensic medicine followed by $2.3 \%$ for Microbiology. In a study conducted across five countries comprising first year students the first preference was for Anatomy (Kumar et al., 2014).

Overall, $19.6 \%$ each of our participants chose Medicine and Surgery as their preferred choice followed by $8.2 \%$ for Paediatrics followed by $6.8 \%$ for Dermatology. In a similar study conducted in Nigeria across four tertiary care teaching centers, the top preferences were for Obstetrics (26.3\%), Surgery $(21.7 \%)$, Paediatrics (11.6\%) and Internal Medicine (10.1\%) (Okonta et al., 2015).

Similar results were observed in the study from Germany as well where $11.7 \%$ students opted for Internal Medicine, 9.77\% for Gynecology, 9.62\% for Paediatrics and $8.85 \%$ for Surgery (Götz et al., 2011). Reports from Malaysia also reported a similar trend (Chew et al., 2011).

In our study, the preference for Gynecology, Paediatrics, Orthopaedics consistently increased from entry level to the exit level batch throughout the course of undergraduate education. This is unlike the findings from Germany where researchers found the preference for Internal Medicine growing exponentially whereas that for surgery reduced (Götz et al., 2011).

More than 58\% students opted for their chosen branches because of their keen interest in that subject. This was followed by $16 \%$ who chose their respective branches since they were well paying. Nearly $10 \%$ students were inclined to their choice of specialty since they had been taught that subject exceptionally well while a small number opted for their branches thinking they were terminal branches and they would not have to pursue super specialty courses in 
them. $15 \%$ had not made up their mind till the time of study. In the study from Nigeria too, 91\% (majority) of students chose their branch of specialization since they had a passion for it (Odusanya et al., 2000). In the study performed across five medical schools in Germany bright career prospects, economic stability and a flare for the subject were cardinal reasons why students chose a specific specialty (Götz et al., 2011). This is similar to findings of our study. In another study from Rajasthan, India too researchers reported interest in the subject, service to community and monetary gains, to be three top factors influencing choice of specialty (Saini \& Hasan, 2016). In a report from Gujarat, India, 42\% students chose their specialty based on reputation assigned to it (Upadhyaya \& Raval, 2015). Only $11 \%$ based their choice primarily on monetary rewards.

Gender based analysis of specialty choice in our study revealed that significantly higher number of women students preferred clinical specialty compared to male students. Numerous studies on the subject have reported gender based preferences within clinical specialties (Kumar et al., 2014; Chew et al., 2011; Saini et al., 2016; Bhat et al., 2012). Our study, though remains the first one to compare gender based preferences between clinical and non clinical (pre and paraclinical) specialties.

Students willing for a more full time work were more likely to opt for internal medicine or general surgery as specialty, while those preferring to work part time were more inclined to choose Psychiatry or family medicine as reported by a Dutch study (Alers et al., 2014). Thus, stronger preference for medicine or surgery in our study could possibly be a reflection of willingness for full time work in the students. We however did not study this parameter as an association for the preference of specialty.

In a study from Australia superior patient access, clinical experience and therefore learning opportunity were reasons why students wanted to join rural hospitals. Students Hailing from rural background were eight times more likely to join rural placement opportunities as compared to their urban counterparts. In our study as well 9.3\% students were willing to join rural placements. The reason cited most commonly being, hailing from rural background and better clinical exposure (Spencer et al., 2008).
Arscott-Mills et al., (2016) has reported that $91 \%$ undergraduate students after completing their rural posting preferred settling in urban areas. Reasons cited for their preference were professional isolation and stagnation of learning. Hays (2017) has concluded that a longer span of rural posting enhanced the chances of students opting a rural destination for practice. Schofield (2009) has found that $45 \%$ of the population studied wanted to practice abroad in the coming five years after medical graduation.

Ten percent students in our study expressed the intent to settle abroad. This is in contrast to studies from Ireland where $38 \%$ students by the end of the undergraduate course were keen to move base (Gouda et al., 2015). The reasons cited for the same being standard of training and monetary gains. Deressa and Azazh (2012) from Ethiopia also stated that $53 \%$ students willing to move abroad after medical graduation. The inclination towards emigration was higher among senior students as compared to junior students. In a multicentric study published in a recent Bulletin of the WHO, $26 \%$ medical students expressed their intent to work abroad within five years of completing graduation. The study population consisted of students from ten institutes from sub Saharan Africa and six from South East Asia. The desire for post graduate speciality training correlated with the aspiration of an international career (Silvestri et al., 2014). This finding does not corroborate with our study where nearly all the students want to pursue post graduation but only $10 \%$ are willing to emigrate.

Work life balance $(78 \%)$, choice of specialty $(20.7 \%)$ and financial gains $(20 \%)$ were the top three priorities in the life of young undergraduates in our study. A Swedish study reported that majority of final year students counted work life balance as a top priority and the trend that was emerging was more of "work to live" than "live to work" (Diderichsen et al., 2011).

This study has wide ranging implications in the formation of national policies.

1. Passion for the subject is the paramount reason to choose a specialty.

2. Money does not quite make the world go round in all cases.

3. Enhanced technological proficiency probably is associated with better decision 
making prowess and higher aspiration for higher study.

4. Technological proficiency does not parallel interest in research and academics.

5. Research and faculty position appear less rewarding to medical students in the present scenario. There appears to be a need to make these fields more lucrative and impressive in print and electronic media so as to attract more talent in these arenas.

6. All fertile minds are not craving to settle abroad or join lucrative corporate career placements.

\section{Conclusion}

Passion for medicine and a desire to serve were the main reasons why students opted for medical career. Majority (88.5\%) students wanted to study clinical subjects in post graduation. General Medicine and General Surgery were the most coveted specialties opted for by undergraduate students.

Nearly half of the population studied wanted to pursue post graduation and a similar number aspired to super specialize. Passion for the subject, monetary gains and how well the subject was taught were the three main bases for the choice of specialty. The preference for clinical branches increased consistently with each year of study and women students were significantly more likely to choose a clinical specialty than their male counterparts. Majority of students wanted to serve in government sector after study but only $5 \%$ wanted to become faculty or pursue research.

Despite becoming more technology savvy with years of medical training students consistently preferred chalk and board teaching over audio visual aids for teaching purposes. Last but not least, work life balance remained the top priority for more than $78 \%$ students in their future lives.

\section{Conflict of Interest}

The authors declare no conflicts of interest.

\section{References}

Alers, M., Pepping, T., Bor, H., Verdonk, P., Hamberg, K. \& Lagro-Janssen, A. (2014) Speciality preferences in Dutch medical students influenced by their anticipation on family responsibilities, Perspectives on Medical Education, 3, pp. 443.
Arscott-Mills, T., Kebaabetswe, P., Tawana, G., Mbuka, D.O., Makgabana-Dintwa, O., Sebina, K., Kebaeste, M., Mokgatlhe, L. \& Nkomazana, O. (2016) Rural exposure during medical education and student preference for future practice location-a case of Botswana, African Journal of Primary Health Care \& Family Medicine, 8, 1, pp. 1039.

Bhat, S., D'souza, L. \& Fernandez, J. (2012) Factors influencing the career choices of medical graduates, Journal of Clinical and Diagnostic Research, 6, pp. 61-64.

Chew, Y.W., Rajakrishnan, S., Low, C.A., Jayapalan, P.K. \& Sreeramareddy, C.T. (2011) Medical students' choice of specialty and factors determining their choice: A crosssectional questionnaire survey in MelakaManipal Medical College, Malaysia, Bioscience Trends, 5, 2, pp. 69-76.

Cleland, J.A., Johnston, P.W., Anthony, M., Khan, N. \& Scott N.W. (2014) A survey of factors influencing career preference in new-entrant and exiting medical students from UK medical schools, BMC Medical Education, 14, 1, pp. 151.

Deressa, W. \& Azazh, A. (2012) Attitudes of undergraduate medical students of Addis Ababa University towards medical practice and migration, Ethiopia, BMC Medical Education, 12, 1, pp. 68.

Diderichsen, S., Andersson, J., Johansson, E.E., Verdonk, P., Lagro-Janssen, A. \& Hamberg, K. (2011) Swedish medical students' expectations of their future life, International Journal of Medical Education, 2, pp. 140.

Götz, K., Miksch, A., Hermann, K., Loh, A., Kiolbassa, K., Joos, S. \& Steinhäuser, J. (2011) Aspirations of medical students:" planning for a secure career"-results of an online-survey among students at five medical schools in Germany, Deutsche medizinische Wochenschrift (1946), 136, 6, pp. 253-257.

Gouda, P., Kitt, K., Evans, D.S., Goggin, D., McGrath, D., Last, J., Hennessy, M., Arnett, R., O'Flynn, S., Dunne, F. \& O'Donovan, D. (2015) Ireland's medical brain drain: migration intentions of Irish medical students, Human Resources for Health, 13, 1, pp. 11.

Hays, R. (2017) The career preferences of students who choose longer duration rural clinical placements, Investigación en Educación Médica, 6, 21, pp. 3-7.

Kumar, A., Mitra, K., Nagarajan, S. \& Poudel, B. (2014) Factors influencing medical students' choice of future specialization in medical sciences: a cross-sectional questionnaire survey from medical schools in China, Malaysia and regions of South Asian association for regional cooperation, North American Journal of Medical Sciences, 6, 3, pp. 119. 
Newton, D.A., Grayson, M.S. \& Thompson, L.F. (2005) The variable influence of lifestyle and income on medical students' career specialty choices: data from two US medical schools, 1998-2004, Academic Medicine, 80, 9, pp. 809-814.

Odusanya, O.O., Alakija, W. \& Akesode, F.A. (2000) Socio demographic profile and career aspirations of medical students in a new medical school, The Nigerian Postgraduate Medical Journal, 7, 3, pp. 112-115.

Okonta, K.E., Akpayak, I.C., Amusan, E.O., Ekpe, E.E., Adamu, Y.B. \& Ocheli, E.O. (2015) Multicenter survey of House officers' choice of Medical specialties in Nigeria: preferences and determining factors, The Pan African Medical Journal, pp. 20

Saini, S. \& Hasan, N. (2016) Assessment of specialization preference among undergraduate medical students \& its influencing factors, International Archives of Integrated Medicine, 3, 3, pp. 134-138.

Schofield, D., Fletcher, S., Fuller, J., Birden, H. \& Page, S. (2009) Where do students in the health professions want to work? Human Resources for Health, 7, 1, pp. 74.
She, L., Wu, B., Xu, L., Wu, J., Zhang, P. \& Li, E. (2008) Determinants of career aspirations of medical students in southern China, BMC Medical Education, 8, 1, pp. 59.

Silvestri, D.M., Blevins, M., Afzal, A.R., Andrews, B., Derbew, M., Kaur, S., Mipando, M., Mkony, C.A., Mwachaka, P.M., Ranjit, N. \& Vermund, S. (2014) Medical and nursing students' intentions to work abroad or in rural areas: a cross-sectional survey in Asia and Africa, Bulletin of the World Health Organization, 92, pp. 750-759.

Spencer, R.J., Cardin, A.J., Ranmuthugala, G., Somers, G.T. \& Solarsh, B. (2008) Influences on medical students' decisions to study at a rural clinical school, Australian Journal of Rural Health, 16, 5, pp. 262-268.

Upadhyaya, S.K. \& Raval, C.M. (2015) Perception of $1^{\text {st }}$ year medical students towards career choices and specialty of psychiatry, Journal of Health Specialties, 3, 1, pp. 35. 